\title{
Successful closure of a refractory rectal anastomotic fistula using endoscopic submucosal dissection combined with an over-the-scope clip
}

Digestive endoscopy is increasingly replacing surgery in the treatment of postoperative leaks and fistulas. However, treatment of patients with these conditions remains challenging with many different methods being currently tested [1].

Here we present a case of a 69-year-old man who underwent Hartmann sigmoidectomy in 2014 for perforated diverticulitis. In September 2016, he underwent stoma reversal with protective ileostomy because of tissue fragility in the area of the anastomosis. A month later, an anastomotic rectal fistula with pericolic abscess collection was confirmed on a computed tomography (CT) scan ( Fig.1). Because the collection was unresponsive to antibiotic treatment, the fistulous tract was later drained with a doublepigtail stent (> Fig. 2 ).

The stent was removed 4 months later and we performed endoscopic submucosal dissection (ESD) of the mucosal patch surrounding the fistulous orifice, in order to ensure maximal excision of the orifice mucosa and increase the chances of successful scarring of the fistula (\$Fig. 3; - Video 1). The exposed area was subsequently closed using an over-the-scope clip (OTSC) system (Ovesco, Tübingen, Germany) ( Fig.4; Video 1). The procedure was considered a technical success; however, the protective ileal stoma was left in place until full confirmation of fistula resolution and normal colonic passage had been obtained. A follow-up CT scan after 2 months confirmed the absence of visible collections or residual

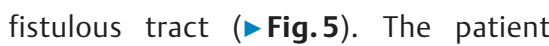
remained well and asymptomatic, and he was scheduled for follow-up colonoscopy and stoma reversal.

There is no generally recommended approach to endoscopic closure of gastrointestinal fistulas. Although the OTSC system is becoming widely used in this setting, in the setting of chronic fistulas, long-term clinical success occurs in only

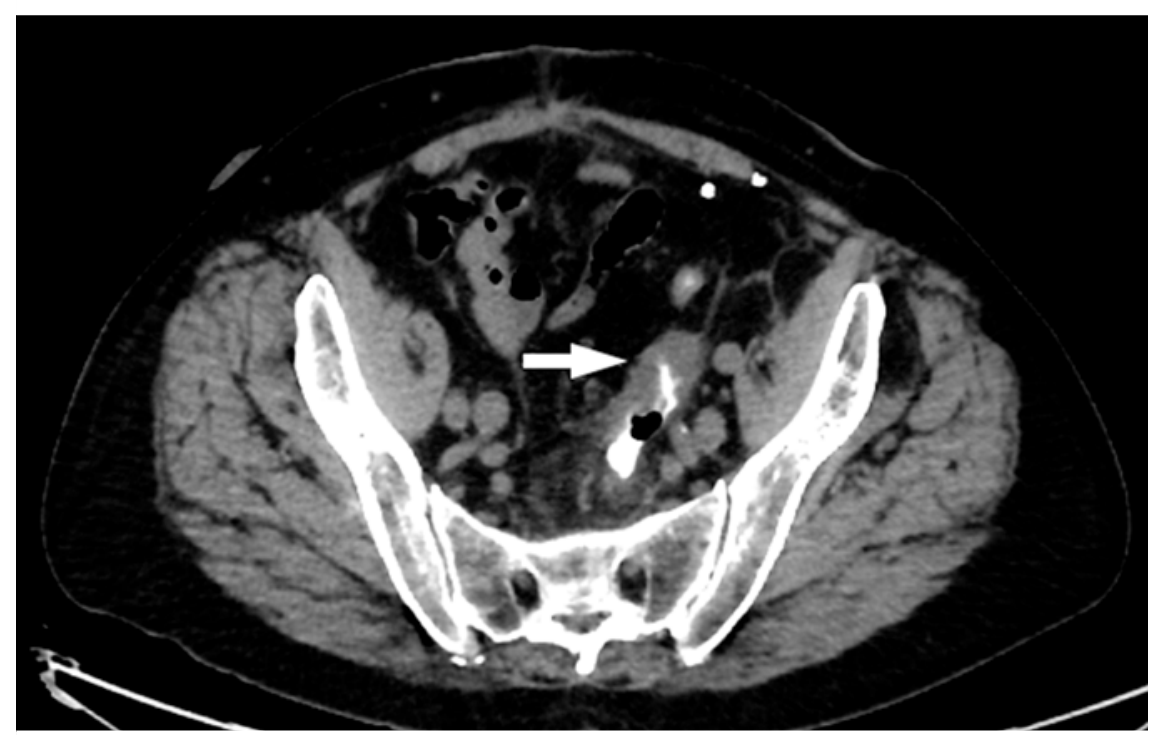

- Fig. 1 Computed tomography scan showing a rectal fistula with a pericolic abscess collection.

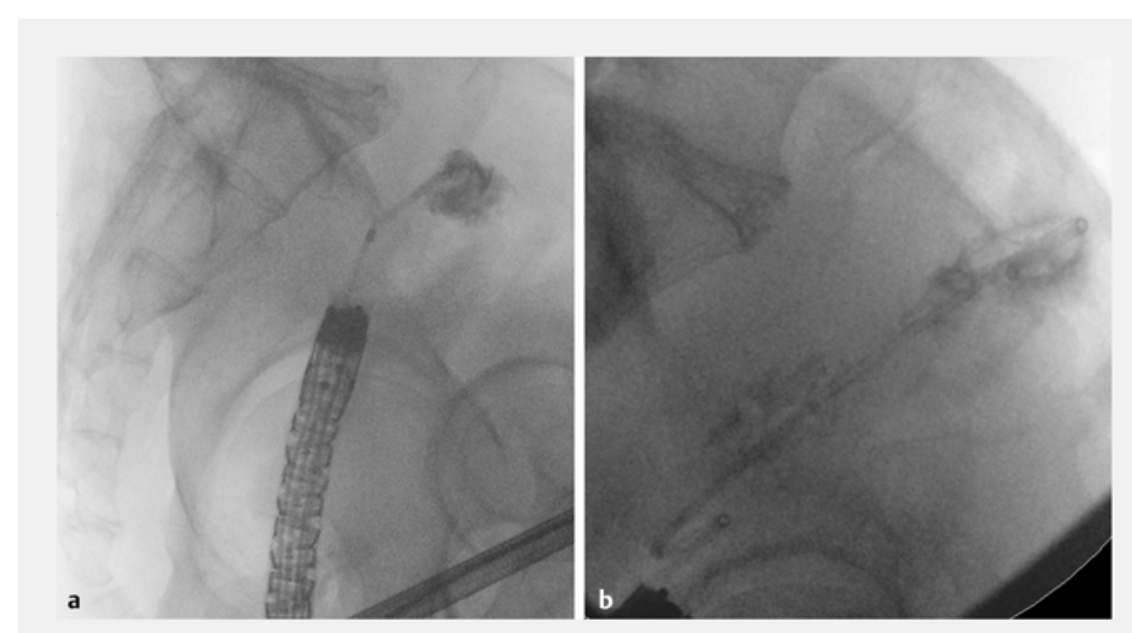

Fig. 2 Radiographic images showing: a opacification of the fistula tract and collection; b double-pigtail catheter drainage of the abscess.

about one-third of patients [2], and previous dissection of the fistula may enhance tissue scarring, as previously demonstrated in esophagotracheal fistulas $[3,4]$.

To summarize, ESD of a fistulous orifice can be a valuable additional tool that may increase the success rates of endoscopic fistula closure using the OTSC system.

Endoscopy_UCTN_Code_TTT_1AQ_2AG 

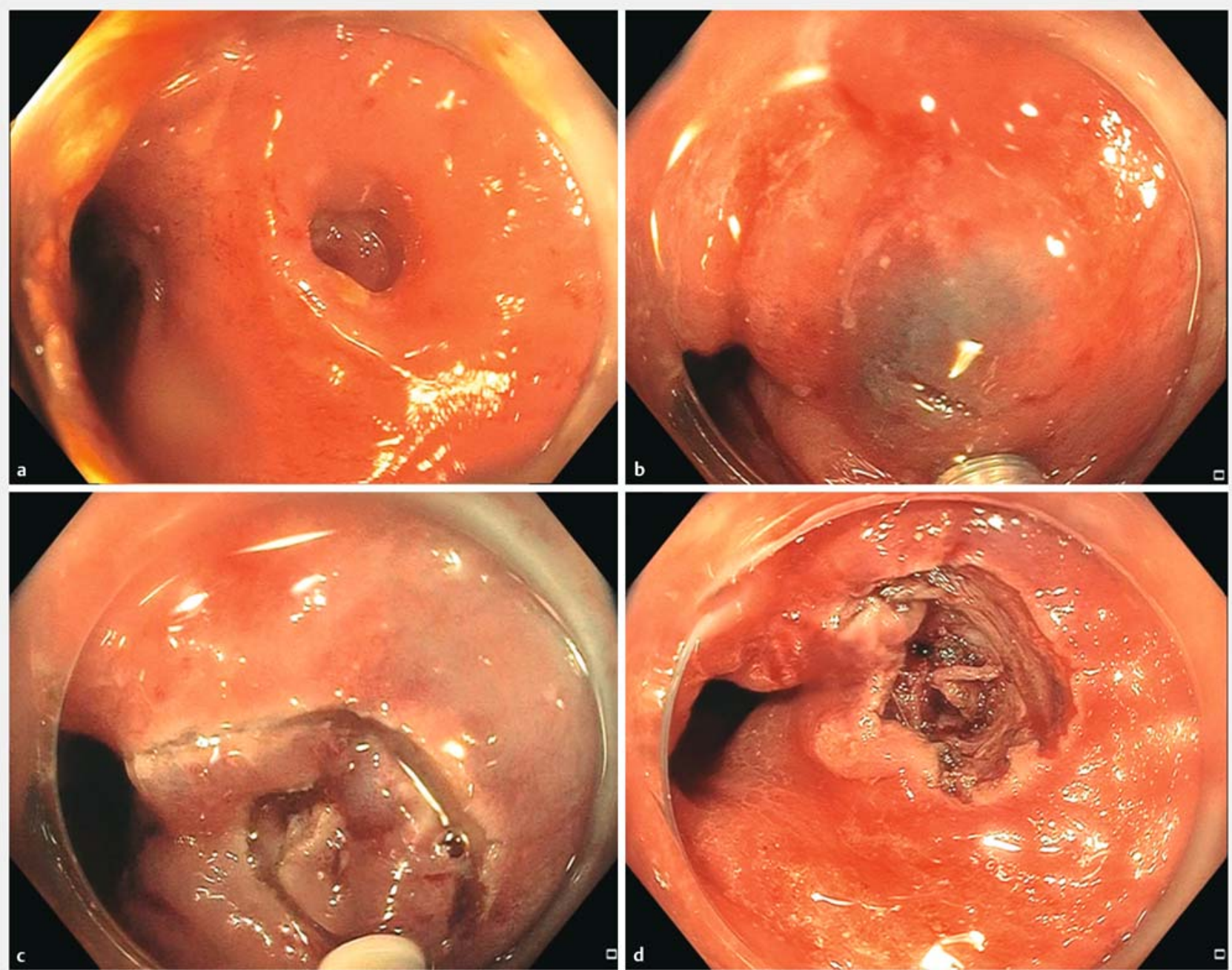

- Fig. 3 Endoscopic submucosal dissection of the mucosal area around fistulous orifice before clip closure. Endoscopic appearance: a of the fistulous orifice; $\mathbf{b}$ following submucosal injection; $\mathbf{c}$ after mucosal incision; $\mathbf{d}$ of the perifistulous mucosal defect after dissection and cold forceps avulsion.

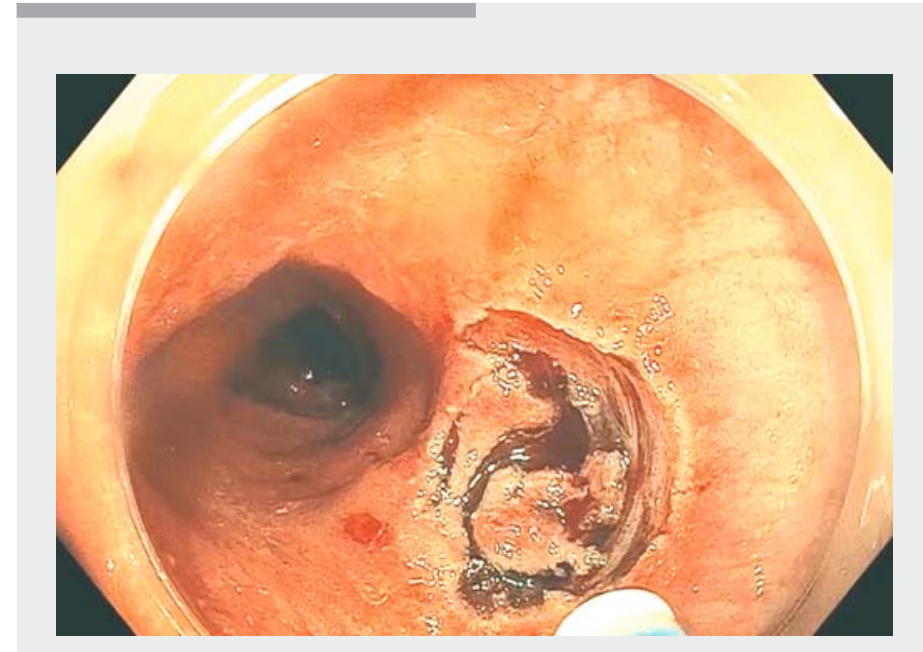

Video 1 Endoscopic submucosal dissection of a patch of mucosa surrounding the fistulous orifice followed by over-the-scope clip (OTSC) closure.
Competing interests

\section{None}

The authors

Neven Barsic ${ }^{1,2}$, Jérôme Rivory ${ }^{1}$, Olivier Monneuse $^{3}$, Jean-Christophe Saurin ${ }^{1}$, Thierry Ponchon ${ }^{1,4}$, Mathieu Pioche ${ }^{1,4}$

1 Department of Endoscopy and Gastroenterology, Pavillon L, Edouard Herriot Hospital, Lyon, France

2 Department of Gastroenterology, Sestre Milosrdnice University Hospital, University of Zagreb School of Medicine, Zagreb, Croatia

3 Department of Digestive Surgery, Edouard Herriot Hospital, Lyon, France

4 Inserm U1032 LabTau, Lyon, France 

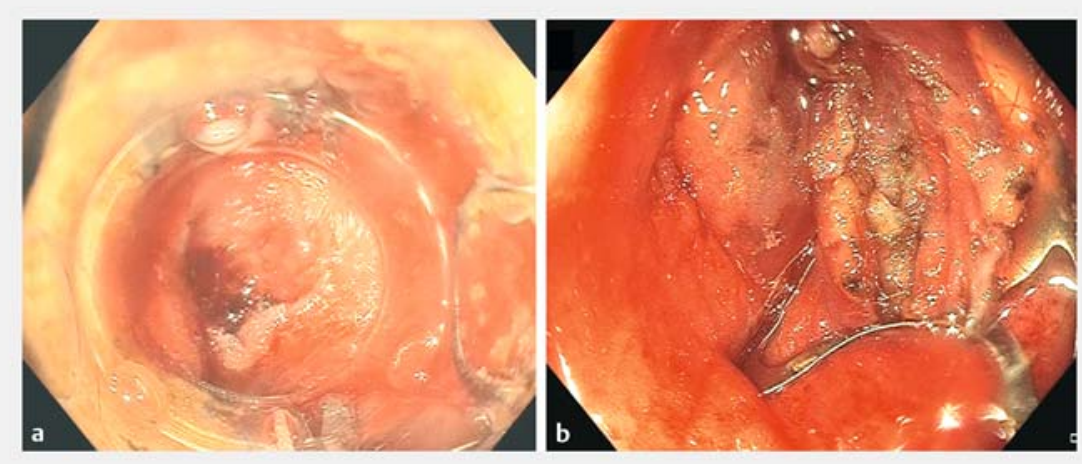

Fig. 4 Endoscopic views showing closure of the exposed perifistulous area using an overthe-scope clip (OTSC; Ovesco).

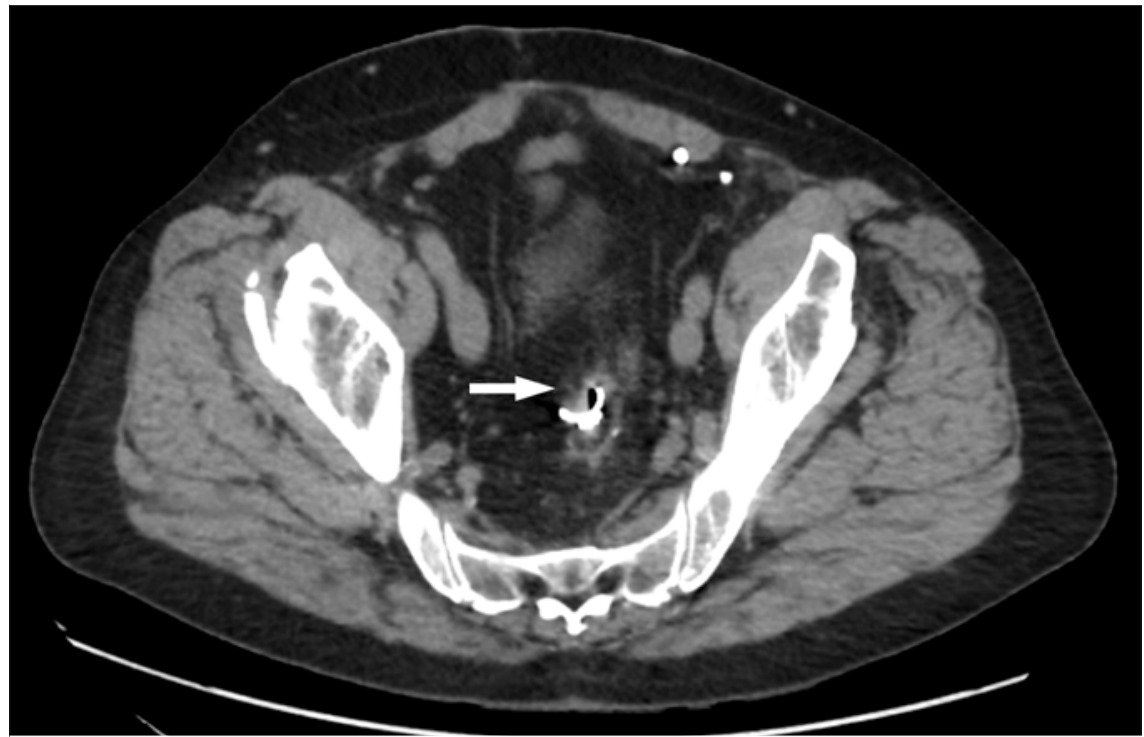

Fig. 5 Follow-up computed tomography scan showing the absence of a residual fistulous tract and no evidence of a collection.
Corresponding author

\section{Mathieu Pioche, MD}

Endoscopy unit - Digestive Disease

department, Pavillon L - Edouard Herriot

Hospital, 69437 Lyon, France

mathieu.pioche@chu-lyon.fr

\section{References}

[1] Goenka MK, Goenka U. Endotherapy of leaks and fistula. World J Gastrointest Endosc 2015; 7: $702-713$

[2] Donatelli G, Cereatti F, Dhumane P et al. Closure of gastrointestinal defects with Ovesco clip: long-term results and clinical implications. Therap Adv Gastroenterol 2016; 9: 713-721

[3] Gruner M, Heissat S, Pitiot V et al. Successfu endoscopic closure of a refractory buttonbattery tracheoesophageal fistula in a 3-year child using endoscopic submucosal dissection of the surrounding mucosa. Endoscopy 2017; 49: E212 - E214

[4] Bertrand G, Jacques J, Rivory J et al. Deep endoscopic submucosal dissection of a refractory tracheoesophageal fistula using clip-and-line traction: a successful closure. Endoscopy 2017; 49: 1278-1280

\section{Bibliography}

DOI https://doi.org/10.1055/s-0044-100612

Published online: 2.2.2018

Endoscopy 2018; 50: E99-E101

(c) Georg Thieme Verlag KG

Stuttgart · New York

ISSN 0013-726X

\section{ENDOSCOPY E-VIDEOS \\ https://eref.thieme.de/e-videos}

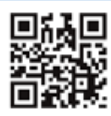

Endoscopy E-Videos is a free access online section, reporting on interesting cases and new

techniques in gastroenterological endoscopy. All papers include a high quality video and all contributions are freely accessible online.

This section has its own submission website at

https://mc.manuscriptcentral.com/e-videos 